\title{
Dynamic Reliability of Continuous Rigid-Frame Bridges under Stochastic Moving Vehicle Loads
}

\author{
Naiwei Lu (D), ${ }^{1,2}$ Kai Wang, ${ }^{1}$ Honghao Wang, ${ }^{1}$ Yang Liu, ${ }^{1,3}$ Yuan Luo, ${ }^{3}$ and Xinhui Xiao ${ }^{3}$ \\ ${ }^{1}$ Engineering Research Center of Catastrophic Prophylaxis and Treatment of Road \& Traffic Safety of Ministry of Education, \\ Changsha University of Science \& Technology, Changsha 410114, China \\ ${ }^{2}$ Industry Key Laboratory of Traffic Infrastructure Security Risk Management, Changsha University of Science and Technology, \\ Changsha 410114, China \\ ${ }^{3}$ School of Civil Engineering, Hunan University of Technology, Zhuzhou 412007, China
}

Correspondence should be addressed to Naiwei Lu; lunaiweide@163.com

Received 17 July 2020; Revised 3 September 2020; Accepted 16 September 2020; Published 25 September 2020

Academic Editor: Songye Zhu

Copyright (c) 2020 Naiwei Lu et al. This is an open access article distributed under the Creative Commons Attribution License, which permits unrestricted use, distribution, and reproduction in any medium, provided the original work is properly cited.

The current volume of freight traffic has increased significantly during the past decades, impacted by the fast development of the national transportation market. As a result, the phenomena of truck overloading and traffic congestion emerge, which have resulted in numerous bridge collapse events or damage due to truck overloading. Thus, it is an urgent task to evaluate bridge safety under actual traffic loads. This study evaluated probabilistic dynamic load effects on rigid-frame bridges under highway traffic monitoring loads. The site-specific traffic monitoring data of a highway in China were utilized to establish stochastic traffic models. The dynamic effect was considered in a vehicle-bridge coupled vibration model, and the probability estimation was conducted based on the first-passage criterion of the girder deflection. The prototype bridge is a continuous rigid-frame bridge with a midspan length of $200 \mathrm{~m}$ and a pier height of $182 \mathrm{~m}$. It is demonstrated that the dynamic traffic load effect follows Gaussian distribution, which can be treated as a stationary random process. The mean value and standard deviation of the deflections are $0.071 \mathrm{~m}$ and $0.088 \mathrm{~m}$, respectively. The dynamic reliability index for the first passage of girder deflection is 6.45 for the current traffic condition. However, the reliability index decreases to 5.60 in the bridge lifetime, accounting for an average traffic volume growth ratio of $3.6 \%$.

\section{Introduction}

In the design phase of a bridge, the structural safety is usually evaluated considering design traffic loads, which were formulated according to large traffic monitoring data during the past decades $[1,2]$. However, the current or future vehicle load might be beyond the design value with the rapid development of transportation industry. As a result, numerous bridges were collapsed or badly damaged due to truck overloading [3-5]. In case that growing traffic load is becoming more and more critical for in-service bridges, the bridge safety under actual traffic loads deserves investigation. The traffic load effect on a bridge is stochastic due to the random nature of traffic loads [6]. In addition, a moving vehicle leads to dynamic effects motivated by the road roughness and the bridge deflection. In view of the above reasons, the structural dynamic reliability theory is appropriate for the safety evaluation of existing bridges under actual stochastic traffic loads. In addition, the design vehicle load model can be calibrated with the target reliability index.

In general, the dynamic effect induced by a moving vehicle can be evaluated in a vehicle-bridge interaction system [7, 8]. A great number of literatures focus on dynamic traffic load effects on both short-span and long-span bridges. Chen and $\mathrm{Wu}$ [9] investigated dynamic effects of a cable-stayed bridge under stochastic vehicle loads and investigated influence of the sparse and dense states of traffic loads on the probabilistic characteristics of bridge load effect. $\mathrm{Lu}$ et al. [10] evaluated lifetime deflection of a suspension bridge considering dynamic and growing traffic loads. Zhou 
and Chen [8] investigated probabilistic characteristics of the dynamic response of a cable-stayed bridge under wind load and stochastic vehicle load. Lu et al. [11] investigated the first-passage probability of a cable-stayed bridge under stochastic vehicle loads. Obrien et al. [12] investigated the dynamic increment of extreme traffic loading on short-span bridges. Jiang et al. [13] investigated the fatigue damage of cables of cable-stayed bridge under combined effect of traffic and wind. Li et al. [14] investigated the safety of suspenders of Tsing Ma Bridge under traffic loads However, there are relatively few studies on probabilistic dynamic traffic load effects on long-span continuous rigid-frame bridges. The unique feature for the continuous rigid-frame bridge is the high-rise piers, which are usually space-flexible, affecting the dynamic behaviour of the bridge. Thus, the probabilistic dynamic traffic load effects on continuous rigid-frame bridges deserve more investigation.

Most studies treated the traffic load effect on a bridge as a random variable. In practice, the load effect on a bridge is a time-varying random process [15]. The commonly used theoretical basis for the probabilistic dynamic analysis of bridges under vehicle load is the first-passage criterion $[16,17]$. The first-passage failure probability is usually estimated based on Rice's level-crossing principle [18]. However, applications of the first-passage theory are mostly concentrated in seismic engineering, while the application to traffic load analysis is relatively insufficient. The bottleneck is that the root mean square of traffic load effects is usually evaluated in frequency domain, while the vehicle-bridge coupled vibration is mostly analysed in time domain [19]. Therefore, the key point is how to extract the probability parameters from the dynamic load effect.

This study evaluated probabilistic dynamic traffic load effects on rigid-frame bridges under highway traffic monitoring loads. The site-specific traffic monitoring data were utilized to establish stochastic traffic models. The dynamic effect was considered in a vehicle-bridge coupled vibration model, and the probability estimation was conducted based on the first-passage criterion of the girder deflection. The prototype bridge is a continuous rigid-frame bridge with mid-span length of $200 \mathrm{~m}$ and pier height of $182 \mathrm{~m}$. It is demonstrated that the dynamic traffic load effect follows Gaussian distribution and thus can be treated as a stationary random process. Parametric studies were conducted, accounting for the road roughness condition, the bridge span length, and the traffic growth ratio.

\section{Theoretical Basis of Probabilistic Traffic- Bridge Interaction Analysis}

2.1. Traffic-Bridge Interaction Model. A vehicle passing on a bridge leads to the vibration of the bridge due to the road surface roughness [20]. Meanwhile, the vibration of the bridge impacts the vibration of the vehicle. Thus, the vehicle-bridge interaction is a coupled vibration system. Figure 1 shows the plane motion model of two-axle vehicle, where $x$ represents the road roughness and $C$ and $K$ represent the damping and stiffness parameters, respectively. The vehicle model has four degrees of freedom including vertical motion of two axles and the motion and rotation of the vehicle body.

Based on the simplified model as shown in Figure 1, the differential equation of motion of the vehicle-bridge coupled system can be written as [21]

$$
\begin{aligned}
& M_{v} \ddot{u}_{v}+C_{v} \dot{u}_{v}+K_{v} u_{v}=F_{v g}+F_{v b}, \\
& M_{b} \ddot{u}_{b}+C_{b} \dot{u}_{b}+K_{b} u_{b}=F_{b g}+F_{b v},
\end{aligned}
$$

where $M_{v}$ and $M_{b}$ represent the mass matrix of the vehicle and that of the bridge, respectively; $C_{v}$ and $C_{b}$ represent the damping matrix of the vehicle and that of the bridge, respectively; $K_{v}$ and $K_{b}$ represent the stiffness matrix of the vehicle and that of the bridge, respectively; $u_{v}$ and $u_{b}$ represent the displacement vector of the vehicle and that of the bridge, respectively; $F_{v b}$ and $F_{b v}$ represent the interaction forces between the vehicle and the bridge; $F_{v g}$ and $F_{b g}$ represent the weight of the vehicle and that of the bridge, respectively.

In order to consider the multiple-vehicle effect on the bridge response, this study utilized an equivalent dynamic wheel load (EDWL) approach proposed by Chen and Cai [22]. Based on the EDWL approach, the force of the $j$ th vehicle on a bridge can be simplified as a time-varying force, which can be written as

$$
\begin{aligned}
\{F(t)\}_{\mathrm{Eq}}^{\text {wheel }} & =\sum_{j=1}^{n_{v}}\left\{\left[1-R_{j}(t)\right] G_{j} \cdot \sum_{k=1}^{n}\left\{h_{k}\left[x_{j}(t)+\alpha_{k}\left[x_{j}(t) d_{j}(t)\right]\right]\right\}\right\} \\
R_{j}(t) & =\frac{\operatorname{EDWL}_{j}(t)}{G_{j}} \\
\operatorname{EDWL}_{j}(t) & =\sum_{i=1}^{n_{a}}\left(K_{v l}^{i} Y_{v l}^{i}+C_{v l}^{i} \dot{Y}_{v l}^{i}\right)
\end{aligned}
$$

where $R_{j}$ represents wheel weight ratio of the $j$ th vehicle; $G_{j}$ represents the GVW of the $j$ th vehicle; $x_{j}$ and $d_{j}$ represent longitudinal and lateral positions on the bridge, respectively; $h_{k}$ and $a_{k}$ represent the $k$ th-order vertical and torsional bending modes of the bridge; $n$ and $n_{\mathrm{v}}$, respectively, represent modal orders of bridges and the number of vehicles on the bridges; $K_{v l}^{i}$ and $C_{v l}^{i}$ represent stiffness and damping matrixes of the vehicle, respectively; $Y_{v l}^{i}$ and $\dot{Y}_{v l}^{i}$, respectively, represent the vertical displacement and the velocity of the $i$ th axle; $\mathrm{EDWL}_{j}(t)$ represents the equivalent dynamic axis load of the $j$ th vehicle at time $t$.

The effectiveness of EDWL approach has been verified by $\mathrm{Wu}$ and Chen [23] and $\mathrm{Lu}$ et al. [24] for long-span cablestayed bridges and suspension bridges, respectively. This study develops the EDWL approach in probability analysis and reliability evaluation for continuous rigid-frame bridges.

2.2. First-Passage Criterion. The first-passage criterion is usually utilized for Rice's level-crossing probability analysis of a random process. The principle of Rice's level-crossing is shown in Figure 2, where $t$ is time, $x$ is a random process, 


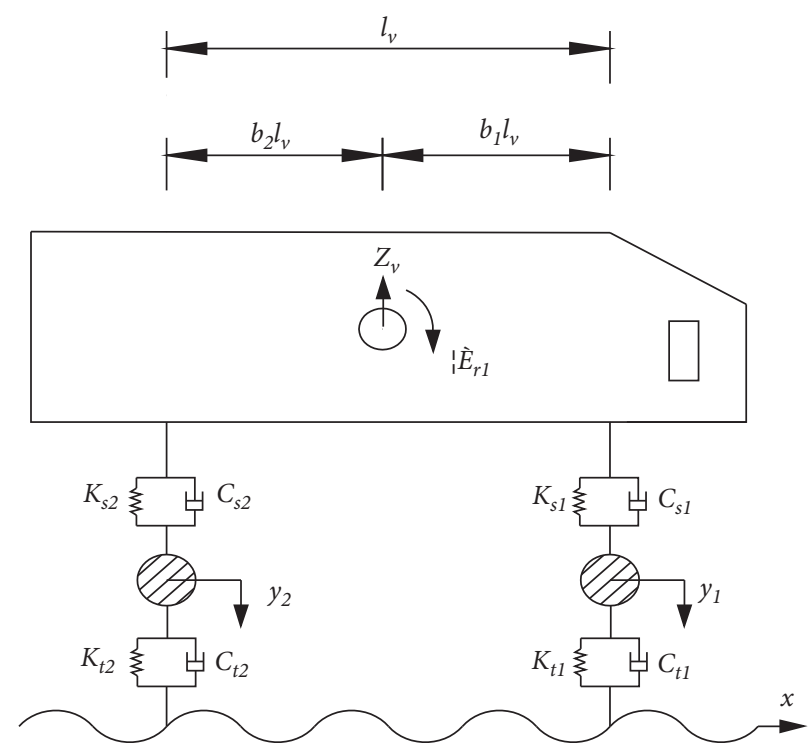

FIgURE 1: Vehicle-bridge coupled vibration system.

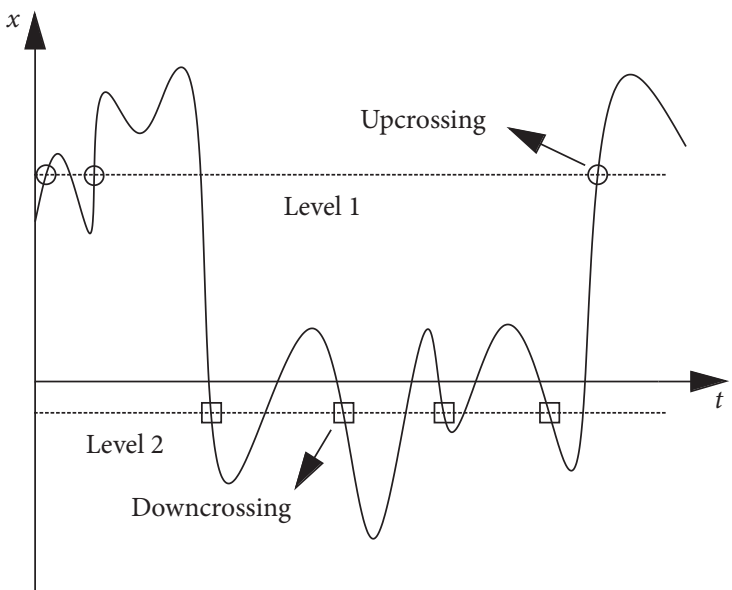

(a)

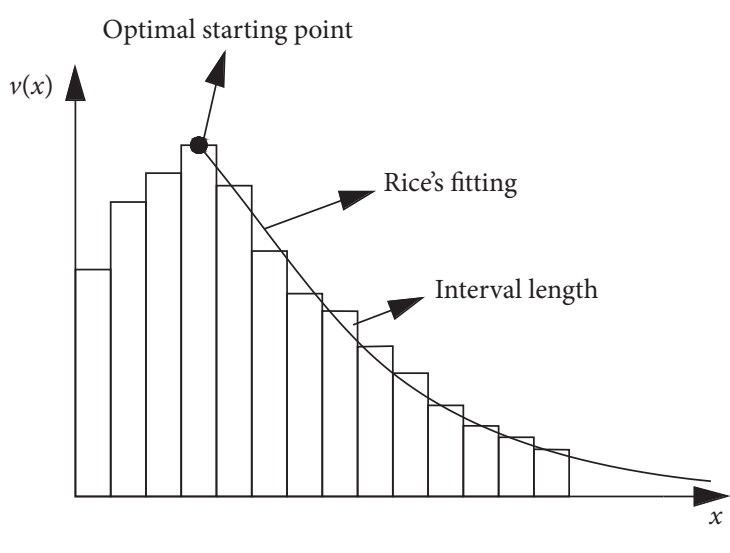

(b)

Figure 2: The level-crossing principle.

that is, the traffic load effect in the present study, and $v(x)$ is the level-crossing rate fitted to the histograms of the number of crossings. Thus, the critical content of the level-crossing theory is to count the number of crossings for the random process.

Suggest that the traffic load effect can be assumed as a Gaussian random process, which will be demonstrated in the case study. For a random process $x(t)$, Rice [25] provided the number of crossings for a level $b$ during time $T$, which is written as

$$
N_{b}(T)=\int_{0}^{T} \int_{-\infty}^{+\infty}|\dot{x}(t)| p_{x \dot{x}}(b, \dot{x}, t) \mathrm{d} \dot{x} \mathrm{~d} t,
$$

where $p_{x \dot{x}}(b, \dot{x}, t)$ is a joint probabilistic density function for $x(\mathrm{t})$ and $\dot{x}(t)$. This function is difficult to estimate for a nonstationary process. Fortunately, the traffic load effect on a bridge can be treated as a stationary random process, as mentioned by researchers [26, 27]. On this basis, the levelcrossing rate $v_{b}(t)$ for a threshold $b$ can be written as

$$
v_{b}(t)=\int_{-\infty}^{\infty}|\dot{x}| p_{x \dot{x}}(b, \dot{x}, t) \mathrm{d} \dot{x} .
$$

For a Gaussian stationary random process with the mean value of zero, the level-crossing probability can be simplified further as

$$
v_{b}=\frac{1}{2 \pi} \frac{\sigma_{\dot{x}}}{\sigma_{x}} \exp \left[-\frac{b^{2}}{2 \sigma_{x}^{2}}\right],
$$

where $v_{b}$ is a constant for level $b$ and $\sigma_{x}$ is the root mean square value. In addition, the number of level-crossings of stochastic traffic load effects can be assumed as Poisson 
distribution. Therefore, the probability of exceeding a threshold can be written as

$$
P_{r}(b)=\exp \left[-v_{b} \cdot T\right]
$$

Note that the accuracy of the estimation mostly depends on the fitting to the curves as shown in Figure 2. In addition, a higher threshold $b$ will result in a more reliable estimation. In general, the mean value of the traffic load effect on a bridge is not zero, which is different from seismic load effects. Therefore, this study developed the above procedures to a nonzero mean value process, which is rewritten as

$$
v_{b}=\frac{1}{2 \pi} \frac{\sigma_{\dot{x}}}{\sigma_{x}} \exp \left[-\frac{\left(b-m_{x}\right)^{2}}{2 \sigma_{x}^{2}}\right],
$$

where $m_{x}$ is the mean value of the traffic load effect.

The density of traffic loads changes with time, where the traffic will be congested and free-flowing for the day and night, respectively. Therefore, the daily vehicle flow was divided into sparse and dense states based on the density of stochastic vehicle model. The probability can be treated as the superposition of the two types of level-crossing probability, which is written as

$$
P_{f}(b, T)=1-\exp \left[-\left(a_{1} \cdot v_{b 1}+\left(1-a_{1}\right) \cdot v_{b 2}\right) T\right],
$$

where $v_{b 1}$ and $v_{b 2}$ represent the level-crossing rates for the congested and free-flowing vehicle flows, respectively; $a_{1}$ and $a_{2}$ represent the proportions of the congested and freeflowing vehicle flows, respectively.

There is a relationship between the structural reliability and the first-passage probability. On this basis, the dynamic reliability can be written as

$$
\beta=\Phi^{-1}\left(1-P_{f}\right)
$$

where $\beta$ is the reliability index, $\Phi()$ is the cumulative distribution function (CDF) of the standard normal distribution, and $\Phi^{-1}()$ is the corresponding inverse function.

2.3. Computational Procedures. Based on the derived formulations of the vehicle-bridge coupled vibration system and the first-passage criterion, a computational framework is essential to combine the components as a system. This study presented a comprehensive framework for dynamic and probabilistic analysis for traffic load effects on rigid-frame bridges based on traffic monitoring data. Figure 3 shows the flow chart of the procedures.

As shown in Figure 3, the framework consists of three main procedures: the stochastic traffic modelling, the trafficbridge interaction analysis, and the probability evaluation. Detailed illustrations of the procedures are shown as follows.

The first step is the stochastic traffic modelling. Initially, the screened traffic monitoring data should be collected from site-specific highways. Subsequently, all vehicles are classified as 6 groups according to the configuration associated with the number of axles. On this basis, the statistical analysis can be conducted for probability modelling of the gross vehicle weight (GVW), the driving lanes, and the vehicle spacing. Finally, the stochastic traffic load model can be simulated utilizing the Monte Carlo simulation (MCS) approach.

The second step is the traffic-bridge interaction analysis. The critical step is to model the dynamic parameters of the vehicle model and the modal parameters of the bridge. Usually, a 2D vehicle model as shown in Figure 1 can be utilized for a relatively precise analysis. The dynamic characteristics of the bridge are considered as mode shapes and natural frequencies. Since the long-span rigid-frame bridge is more complex than a conventional-girder bridge, the numbers of mode shapes and frequencies should be considered as more as possible. Subsequently, the EDWL approach is utilized to convert the moving stochastic traffic flow into time-varying forces. Finally, the time history of traffic load effects can be simulated based on the pseudodynamic analysis.

The third step is the probability evaluation. This step is conducted based on Rice's level-crossing theory. Based on the time histories evaluated from the traffic-bridge interaction analysis, the number of level-crossings can be counted. The number of crossings is formed as histograms, where the level-crossing rate can be fitted accurately as shown in Figure 2(b). Subsequently, the maximum traffic load effect can be extrapolated with consideration of a return period. Finally, the first-passage probability and reliability index can be evaluated based on the assumption of Poisson distribution.

\section{Stochastic Vehicle Flow Simulation Based on WIM Data}

3.1. Probabilistic Modelling of WIM Measurements. Due to the truck overloading behaviour, the GVW usually follows a multimodal distribution. In this regard, this study utilized a Gaussian mixture model (GMM), which is a superposition of several Gaussian models. In practice, the GMM method is widely used in the application of data clustering [28], but it is relatively insufficient in the vehicle weight modelling.

In general, a GMM can be represented as

$$
P\left\{w \mid\left(a_{i}, \mu_{i}, \sigma_{i}^{2}\right)\right\}=\sum_{i=1}^{M} a_{i} \cdot g\left(w \mid \mu_{i}, \sigma_{i}^{2}\right),
$$

where $w$ is the GVW, $a_{i}$ is a weight coefficient, $g$ is a Gaussian distribution function, and $M$ is the number of Gaussian functions. The Gaussian is written as

$$
g\left(w \mid \mu_{i}, \sigma_{i}^{2}\right)=\frac{1}{\sqrt{2 \pi \sigma_{i}}} \exp \left[-\frac{1}{2 \sigma_{i}^{2}}\left(w-\mu_{i}\right)^{2}\right],
$$

where $\mu_{i}$ represents mean value of the $i$ th Gaussian distribution function and $\sigma_{i}$ represents standard deviation of the $i$ th Gaussian distribution function. The parameters of GMMs are usually estimated based on the maximum likelihood optimization. This study utilized the ExpectationMaximization (EM) algorithm to evaluate these parameters. 


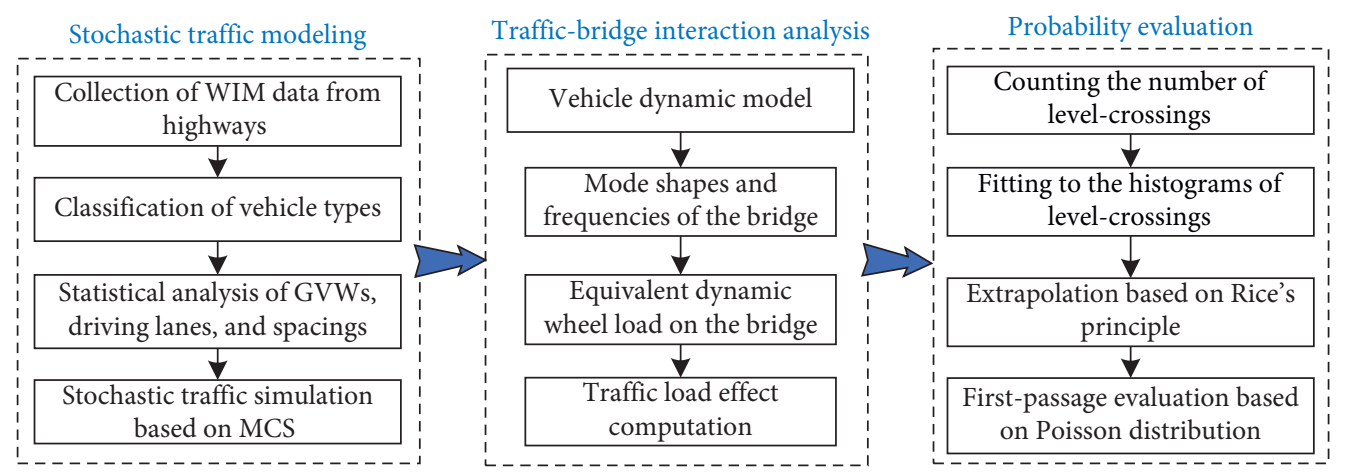

FIgURE 3: Flow chart of the proposed computational framework.

The number of components is estimated based on the Akaike information criterion (AIC) [29].

The authors have conducted extensive analyses on the probability modelling of traffic parameters as shown in the doctoral dissertation [30]. Due to the limit of article, only the probability distributions for 6-axle trucks are provided. Figure 3 plots the fitted probability distribution function (PDF) of the axle weight and the GVW, respectively. In Figure $4, W_{64}$ represents the second axle load of six-axle vehicle.

It is observed that the axle weight and the GVW follow bimodal distribution. In addition, the GMMs have ideally fitted to the empirical histograms. In other words, the GMM has captured the probability behaviour of truck overloading. Note that the threshold weight for 6-axle trucks is $550 \mathrm{kN}$ according to the traffic law in China. It can be observed that half of the 6-axle trucks are overloaded, which is indeed a risk for existing bridges.

3.2. Stochastic Traffic Flow Simulation. With the probability models established based on the weigh-in-motion (WIM) data, this study utilized MCS to establish different types of stochastic traffic flows. The detailed procedures are summarized in Figure 5, where $N_{\mathrm{ADT}}$ is the total number of daily traffic. The programming package MATLAB was utilized to translate the traffic as a matrix that will be called in the subsequent vehicle-bridge interaction analysis.

The preliminary statistical analytical results of the actual traffic monitoring data indicate that the vehicle spacing between two following vehicles follows the Weibull distribution for congested traffic, while it follows Gamma distribution for free-flowing state. Figure 6 plots the sample of a free-flowing stochastic traffic flow, where V1 denotes the lightweight cars and busses, and V2 V6 denote the 2-axle to 6-axle trucks, respectively. Details of the configuration of the vehicle types can be found in [28].

The benefit of the stochastic traffic flow is the probability distribution in accordance with the site-specific traffic monitoring data. In addition, the stochastic traffic model can be updated with the consideration of the traffic volume growth and the limit of truck overloading.

\section{Case Study}

4.1. Backgrounds of the Prototype Bridge. Labajin Bridge, a continuous rigid-frame bridge in Yalu highway of Sichuan in China, is selected as prototype to investigate the deflection of first-passage probability. Site photos of the bridge are shown in Figure 7. The span length of the bridge is $(105+200+200+105) \mathrm{m}$. The bridge is very famous due to the highest piers in the area of Asia, where the length of pier No. 10 is $182 \mathrm{~m}$. The dimensions of the cross sections of boxgirders and piers are shown in Figure 8. The material of the box-girder is C60 concrete. The pier is a composite structure with concrete filled steel tube. The internal and external concrete grades are C80 and C50, respectively.

The finite element model is shown in Figure 9. All of the elements were simulated with beam elements. The boundary condition of the bridge piers is the constraint of all degrees of freedom at the bottom elements. The top nodes of mid-span piers are connected with the closest girder nodes in rigid connection. The top nodes of side-span piers are connected with the closet nodes with the compressive only connection. The top 50 vertical modes of vibration were extracted for the following vehicle-bridge interaction analysis.

4.2. Influence of $R R C$ on Probability Distribution. Since the road roughness condition (RRC) has a significant influence on the vehicle-bridge interaction system, this study selected "good" and "poor" RRCs for the comparative study. The RRCs were simulated by an inverse Fourier transformation function and corresponding power spectral density. The coefficients for "good" and "poor" RRCs are $32 \times 10^{-6} \mathrm{~m}^{3} /$ cycle and $512 \times 10^{-6} \mathrm{~m}^{3} /$ cycle, respectively. Figure 10 plots the time histories of the two types of RRC samples. It is obvious that the poor RRC has a wider fluctuation range compared to the one of good RRC.

The modal analysis of the bridge was conducted firstly considering the modal switches in three space directions. The first 50-order modal shape of the bridge was extracted to solve vehicle-bridge coupled vibration analysis. The damping constant of the concrete was taken as 0.05 . $T$ stochastic vehicle flow samples were transformed as equivalent time-varying concentrated forces based on EDWL method. Subsequently, the time histories of the vehicle load effects were evaluated by utilizing the proposed 


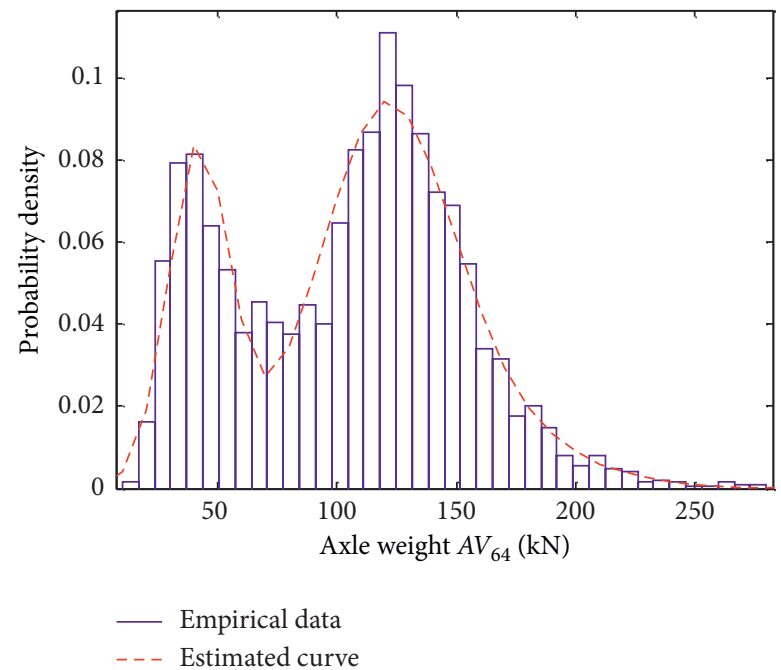

(a)

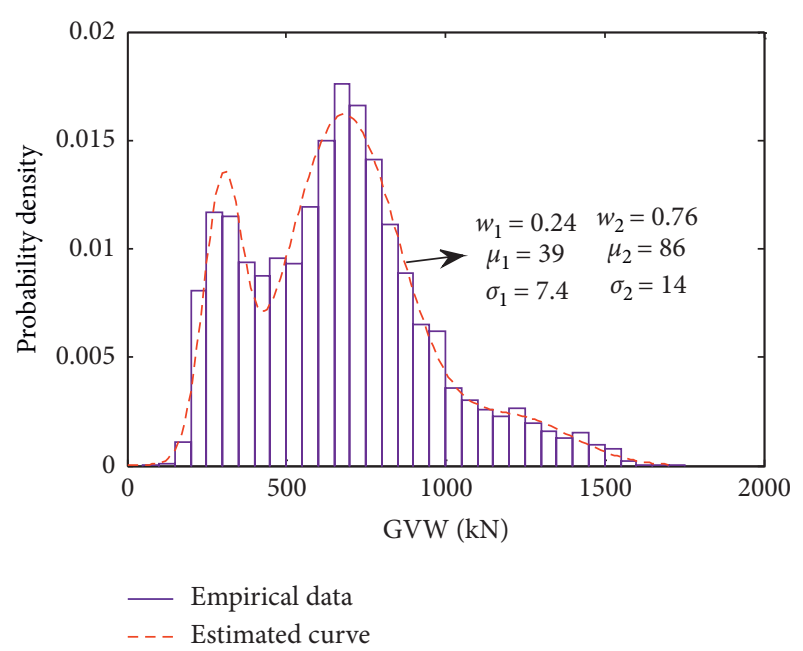

(b)

FIGURE 4: Probabilistic distribution of axle load of 6-axle trucks: (a) axle weight; (b) gross weight.

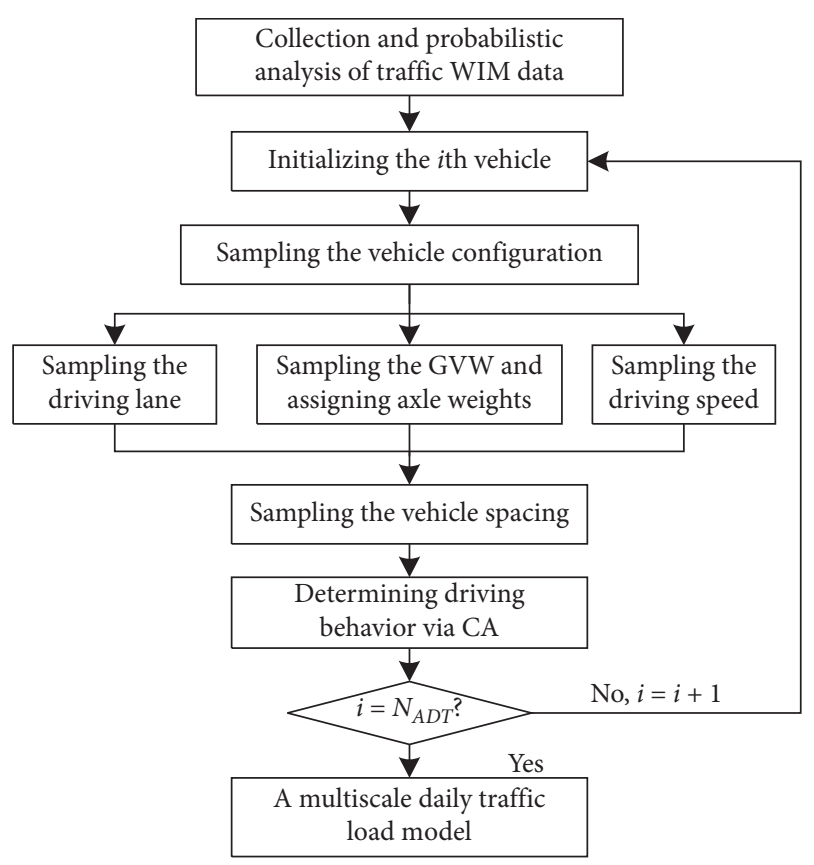

FIGURE 5: Procedures of stochastic vehicle flow simulation.

pseudodynamic approach. Figure 11 plots the vertical deflection histories of the critical point in the mid-span of the bridge accounting for both good and poor RRCs, respectively.

It is observed from Figure 10 that the poor RRC results in more deviations compared with the good RRC. The maximum deflection is located at $162 \mathrm{~s}$, where several heavy trucks load on the mid-span point simultaneously. The maximum deflections for good and poor RRCs are $-0.196 \mathrm{~m}$ and $-0.246 \mathrm{~m}$, respectively. Thus, it is demonstrated that the RRC has a significant influence on the maximum load effect.
Since the basis for extreme value extrapolation is the assumption of Gaussian distribution, the probability distribution should be fitted. Figure 12 plots the histograms of the deflections and the fitted PDF and CDF curves of Gaussian distribution. It is obvious that both good and poor RRCs follow Gaussian distribution. In addition, the shape of histograms for the poor RRC is more flat than that of the good RRC.

The hypothesis testing was conducted to check the fitting to Gaussian distribution. The fitting variances are 0.0028 and 0.0019 for the good and poor RRCs, respectively. It is confirmed that the samples do not refuse the Gaussian distribution. In order to capture the influence of the two types of RRCs on the probabilistic load effect, the histograms of numbers of level-crossings were counted as shown in Figure 13.

As shown in Figure 13, Rice's level-crossings were fitted to the top $30 \%$ samples. It is observed that the poor RRC leads to larger number of level-crossings compared to the good RRC. Based on the above analysis, it can be concluded that the RRC can affect the probabilistic characteristics of traffic load effects, and thus a poor RRC will amplify the maximum traffic load effect.

4.3. Influence of Bridge Span Length on the Dynamic Deflection. In order to investigate the influence of bridge span length on the deflection, both shorter-span and longerspan continuous rigid-frame bridges were selected for comparison study. The main span lengths of the three bridges are $140 \mathrm{~m}, 200 \mathrm{~m}$, and $248 \mathrm{~m}$, respectively. In order to make the comparison of general significance, the same traffic flow as shown in Figure 6 was utilized for the three bridges. The bridge parameters and the maximum deflections are shown in Table 1.

As observed from Table 1, the maximum deflection increases with increase of the bridge main span length. 


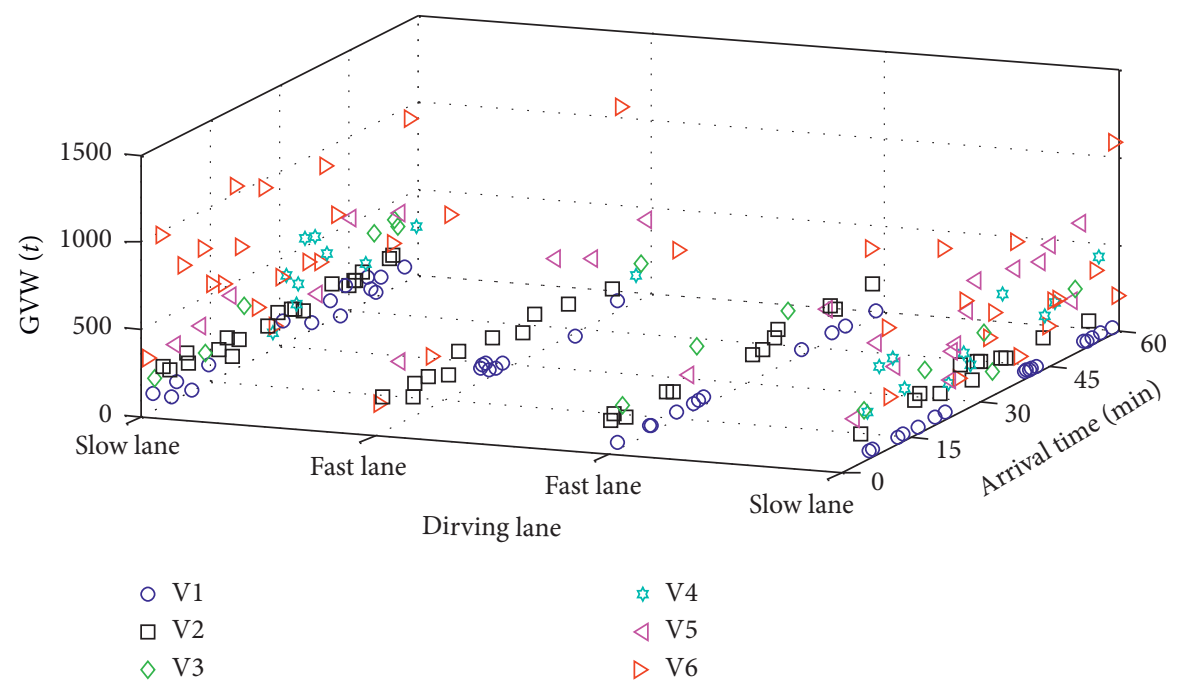

FIgURE 6: A stochastic vehicle flow sample.

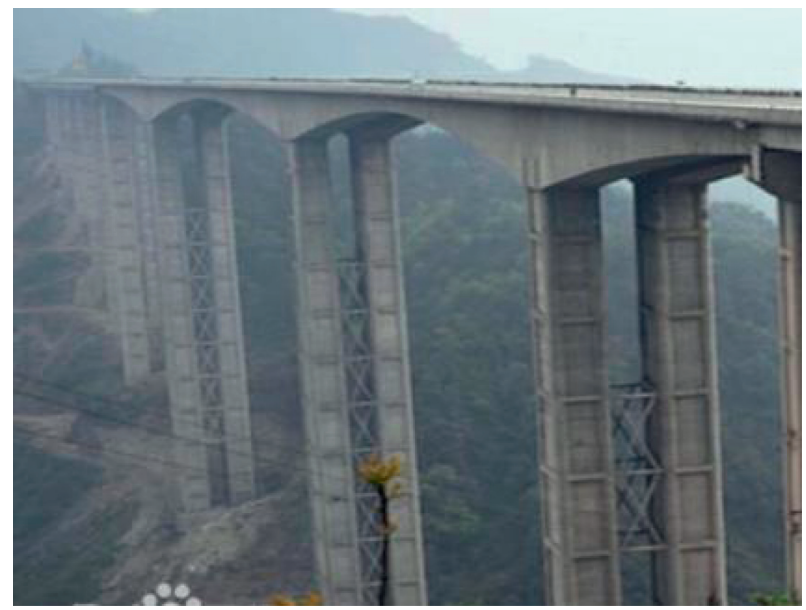

(a)

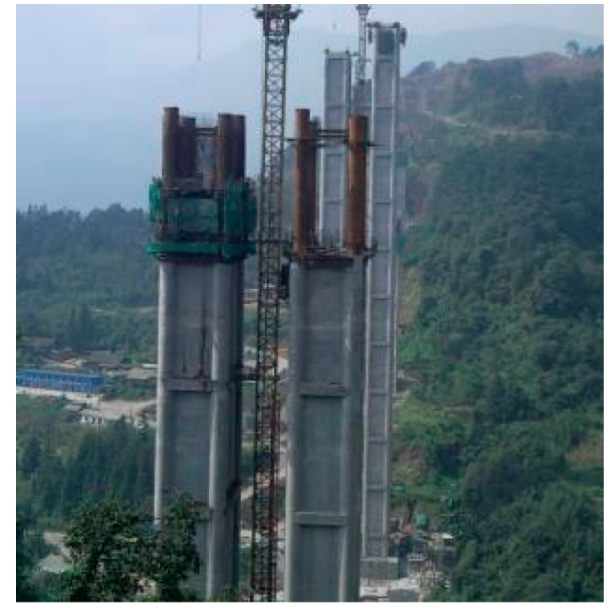

(b)

FIGURE 7: In-site photos of the Labajin bridge in Yalu highway: (a) final state; (b) construction state.

However, the ratio between the good and poor RRC effects decreases with the increase of the bridge span length. This phenomenon can be explained by the theoretical basis that the bridge with a longer span length has a lower frequency, which will weaken the vehicle-bridge interaction. Therefore, the influence of the RRC on the dynamic effect is weakened with the increase of the bridge span length.

4.4. Probability Estimation. It was concluded by many researchers that dynamic response of bridges under stochastic vehicle flow can be assumed as stationary random process [31]. In order to investigate the influence of random process samples on the characteristics of stationary random processes, the mean value and the correlation coefficient in random process were analysed. Figure 14(a) plots the deflection spectrum density of the bridge girder under stochastic traffic flow load. Figure 14(b) plots the autocorrelation coefficient of the samples in $100 \mathrm{~s}, 200 \mathrm{~s}$, and $300 \mathrm{~s}$, respectively.

It is observed that the mean value and standard value of the initial position are greatly affected by 7 seconds. In fact, the mean value and correlation coefficient tend to be constants with the increase of the samplings number. Therefore, if the sample is large enough, this process can be assumed as stationary random process. The random process under stochastic vehicle loads can be represented by the load effects, which was calculated by a large sample of vehicle flows.

The mean value and root mean square deflection of the continuous rigid-frame bridge were obtained by the same method. Figure 15 shows the distribution of mean value and root mean square deflection along the girders.

As observed in Figure 15, the maximum mean value and the root mean square deflection of a continuous rigid-frame 


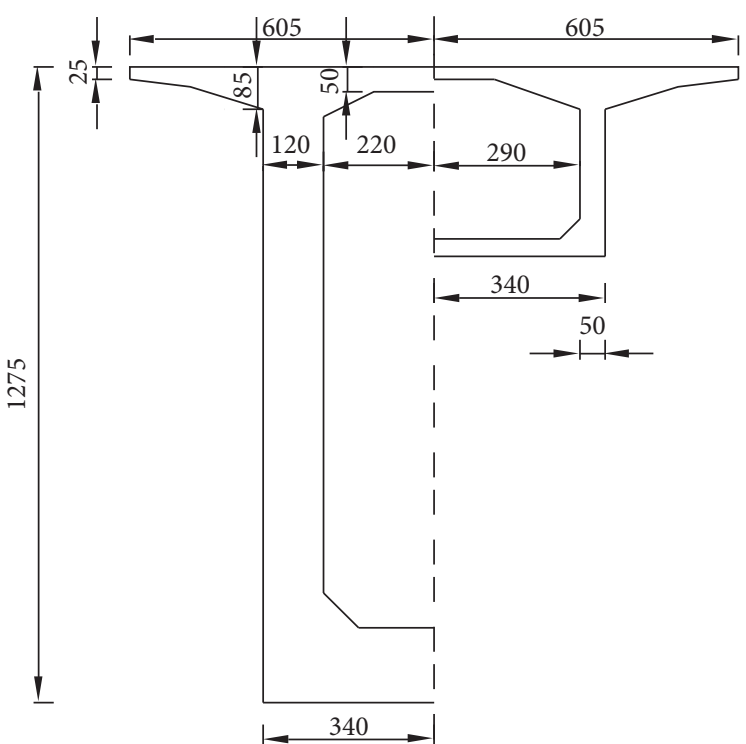

(a)

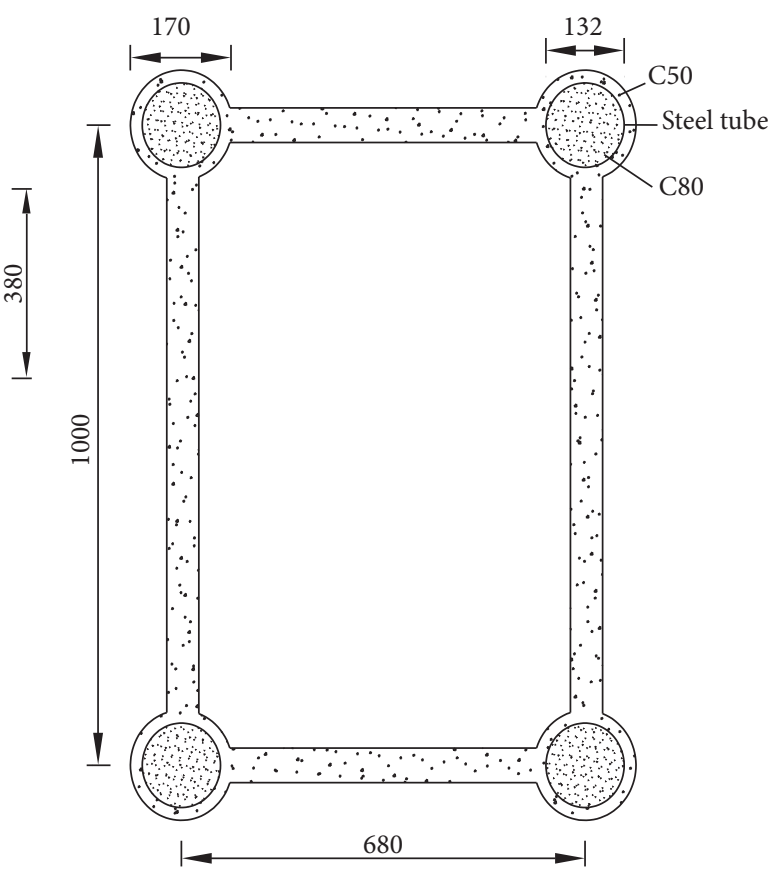

(b)

Figure 8: Dimensions of cross-sections of Labajin Bridge: (a) girders; (b) piers.

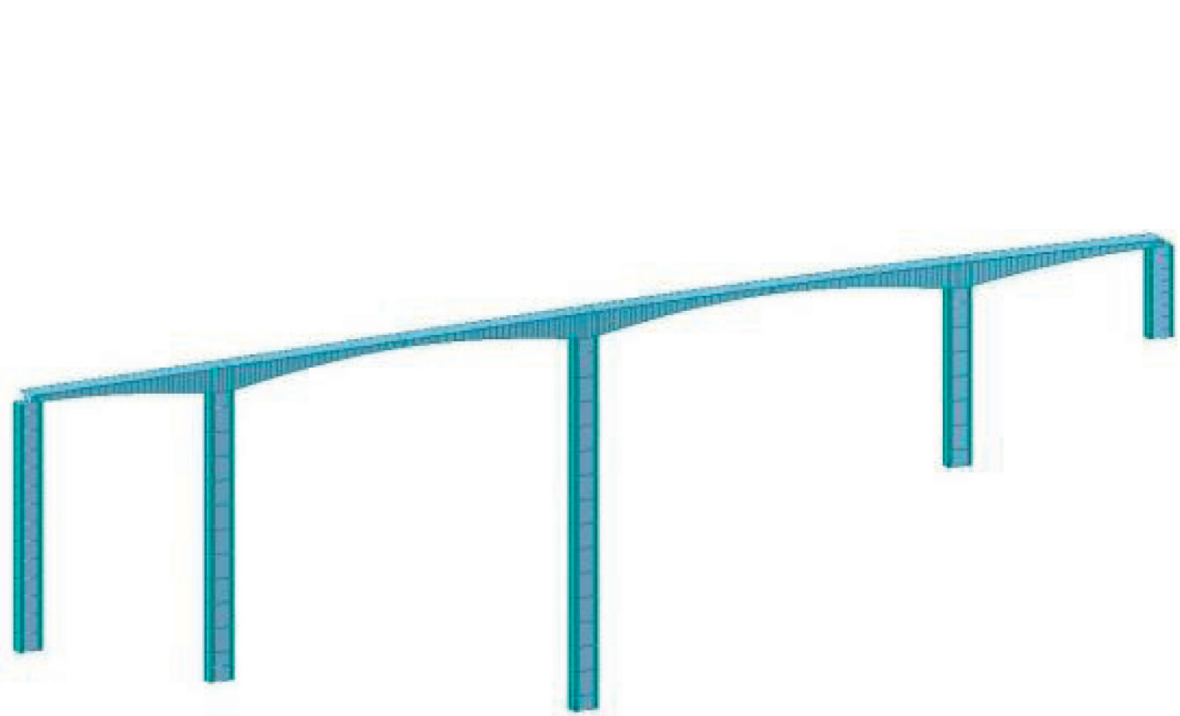

(a)

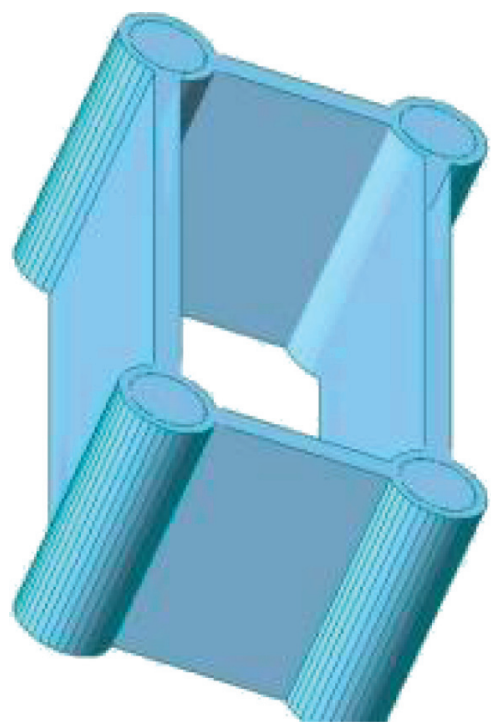

(b)

Figure 9: Continued. 


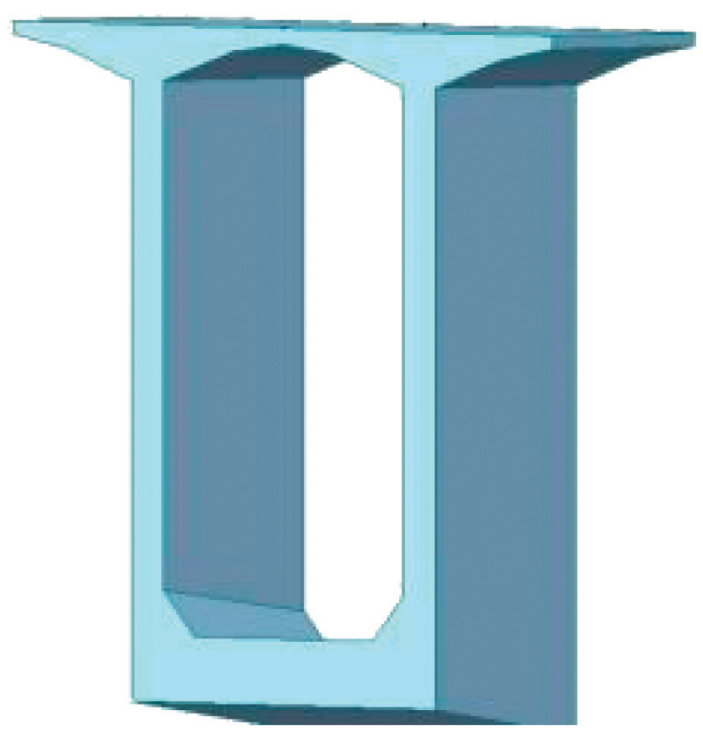

(c)

FiguRe 9: Finite element model of Labajin Bridge: (a) overall model; (b) pier element; (c) girder element.

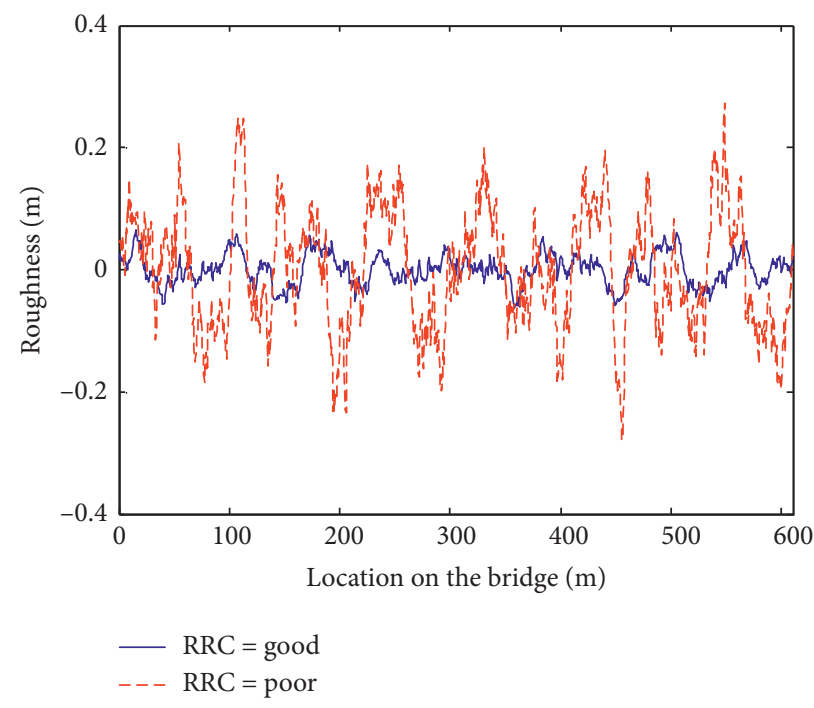

FIGURE 10: Samples of two types of road roughness conditions.

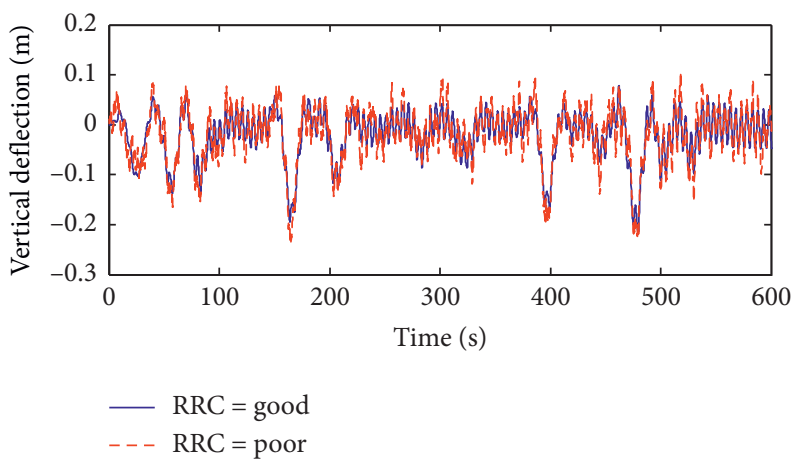

Figure 11: Vertical deflection histories of the critical point in the mid-span of the bridge girders in $10 \mathrm{~min}$. 


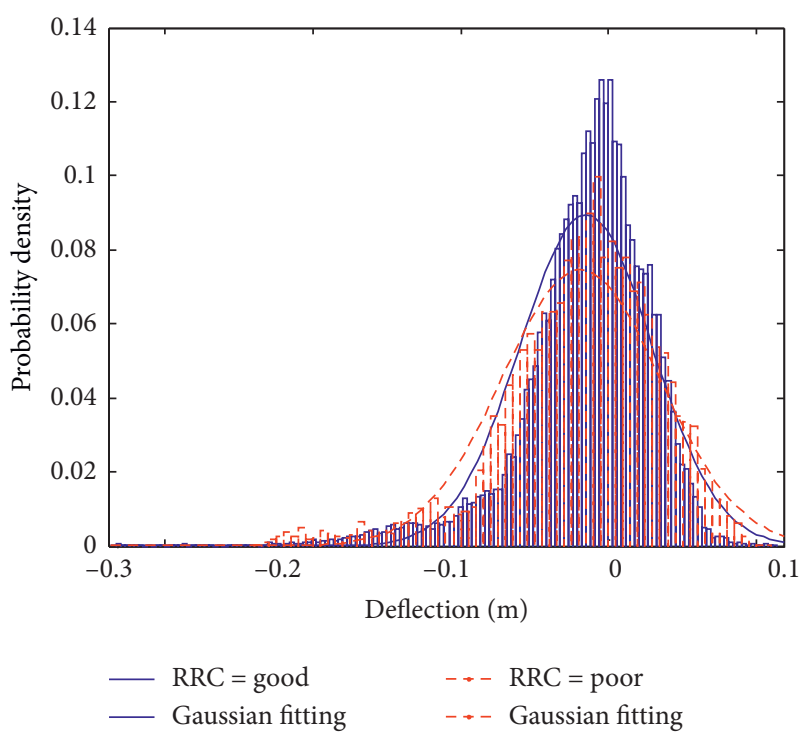

(a)

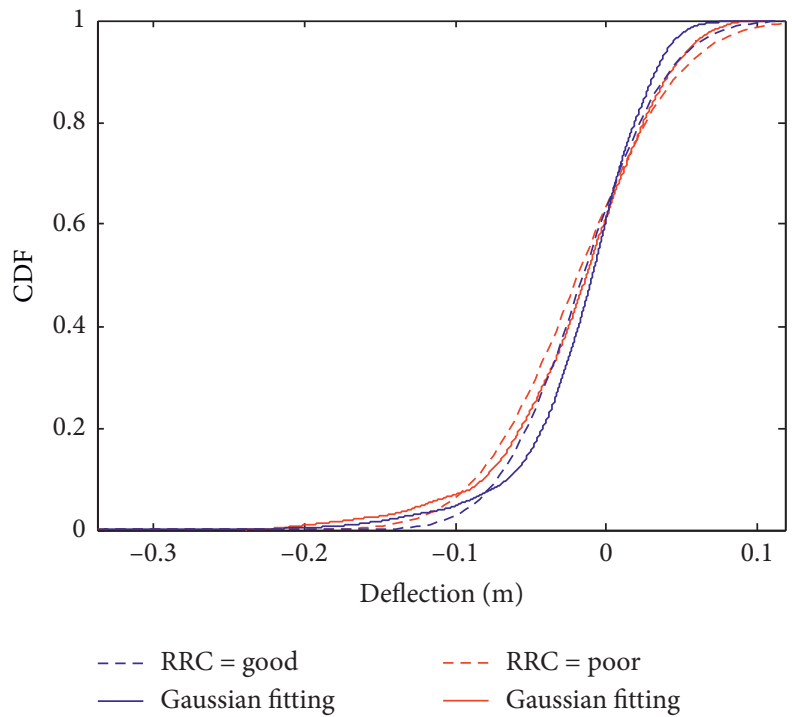

(b)

FIgURE 12: Probability distribution of the critical deflection: (a) PDF; (b) CDF.

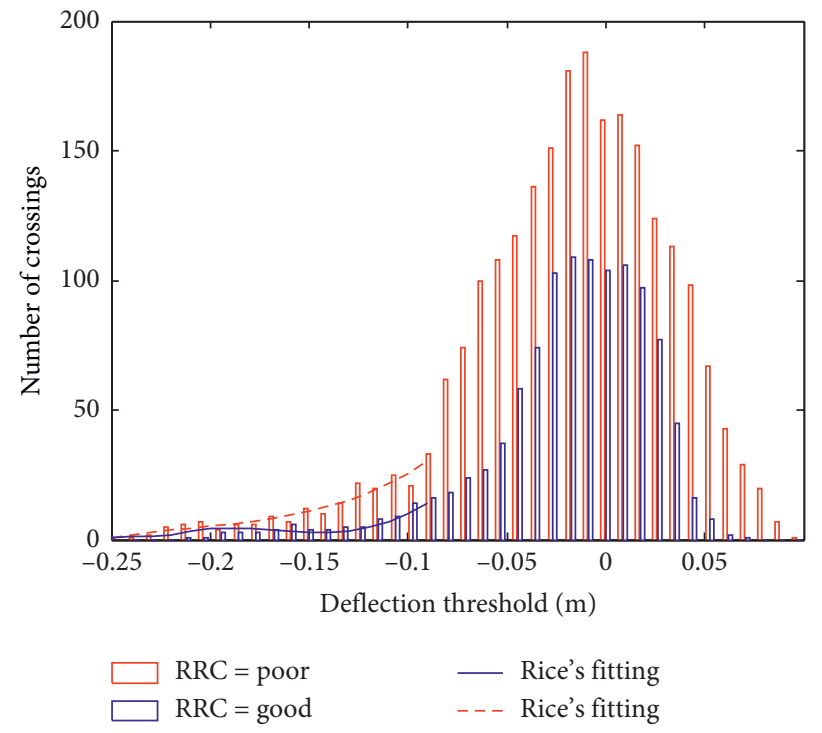

FIGURE 13: Histograms and fitting to the number of level-crossings.

bridge are $-0.071 \mathrm{~m}$ and $0.088 \mathrm{~m}$, respectively. Therefore, this study selected the mid-span point as representation. The following investigation will focus on the deflection of the critical point under stochastic traffic loads.

4.5. First-Passage Reliability Evaluation. In general, the firstpassage reliability analysis can be conducted based on probabilistic model associated with maximum extrapolation. The upper threshold deflection of a continuous rigid-frame bridge is $a=L / 500=0.4 \mathrm{~m}$ according to designed codes in China. Figure 16 shows the time-varying reliability index based on the first-passage criterion of the maximum girder deflection.

As shown in Figure 16, the initial reliability index of the bridge is 6.45. However, the reliability index decreases significantly with the time and the proportion of dense traffic flow. With consideration of the proportion of dense traffic flow as $1.2 \%, 2.4 \%$, and $3.6 \%$, the corresponding reliability indexes of the bridge in 100 years are $5.76,5.62$, and 5.60, respectively. Therefore, it is concluded that the proportion of dense vehicle flow has significant influence on the first-passage probability of the bridge deflection. Thus, the control of dense vehicle 
TABLE 1: Critical parameters of three continuous rigid-frame bridges.

\begin{tabular}{|c|c|c|c|c|c|}
\hline \multirow{2}{*}{ Bridge name } & \multirow{2}{*}{ Span combination $(\mathrm{m})$} & \multirow{2}{*}{ Height of the $0 \#$ segment $(\mathrm{m})$} & \multicolumn{2}{|c|}{ Maximum deflection (m) } & \multirow{2}{*}{$\begin{array}{c}\text { Dynamic ratio between poor } \\
\text { and good RRCs }\end{array}$} \\
\hline & & & $\mathrm{RRC}=$ good & $\mathrm{RRC}=$ poor & \\
\hline Shizijing River Bridge & $74+140+74$ & 8.0 & -0.137 & -0.182 & 1.32 \\
\hline Labajin Bridge & $105+200+200+105$ & 12.5 & -0.196 & -0.246 & 1.25 \\
\hline Lengshui River Bridge & $130+248+130$ & 16.0 & -0.254 & -0.273 & 1.07 \\
\hline
\end{tabular}

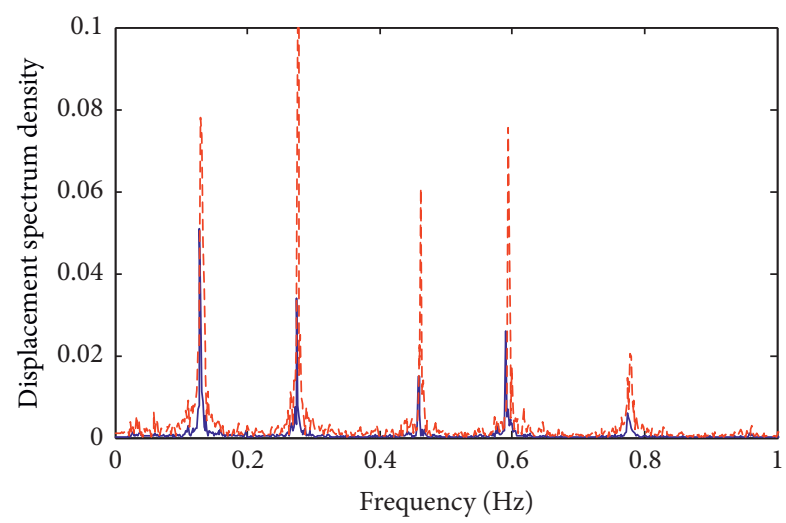

- Free traffic

- - - Busy traffic

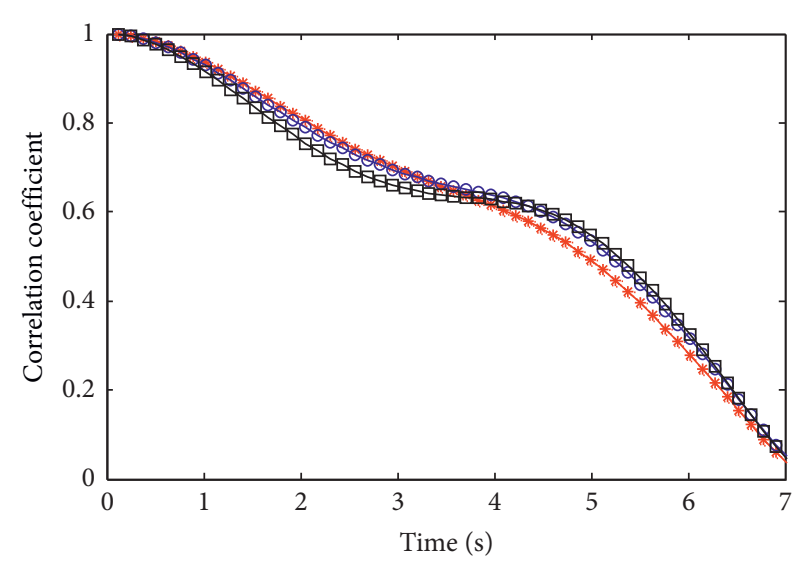

$$
\begin{aligned}
& \rightarrow t=100 \mathrm{~s} \\
& \rightarrow t=200 \mathrm{~s} \\
& \rightarrow \quad t=300 \mathrm{~s}
\end{aligned}
$$

(b)

Figure 14: Bride dynamic deflections in frequency domain: (a) spectrum density; (b) correlation coefficient.

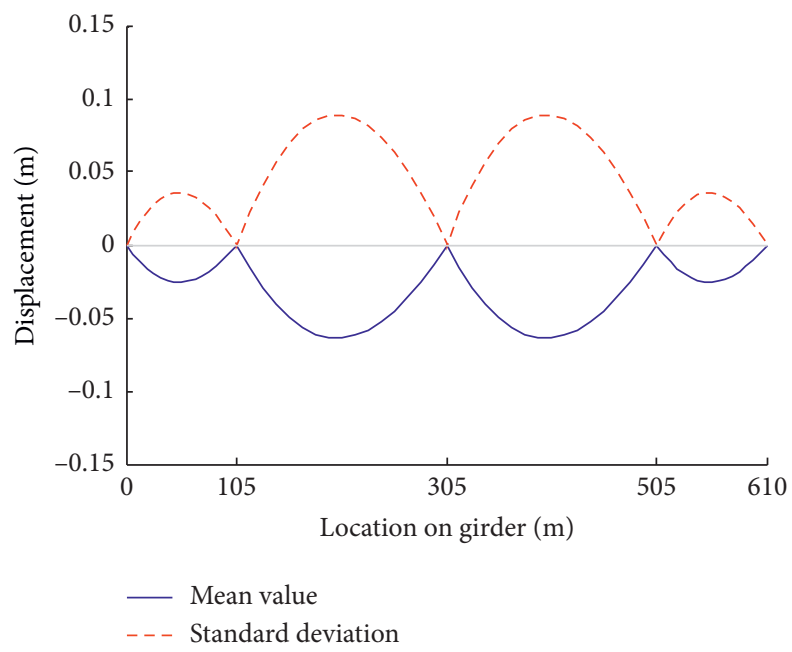

FIgURE 15: Trends of mean value and root mean square of displacement along the girders. 


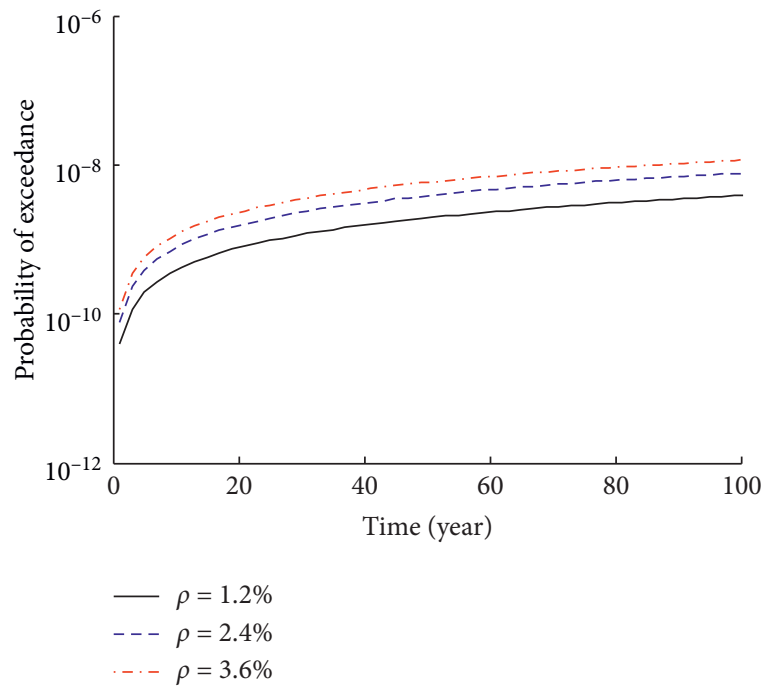

(a)

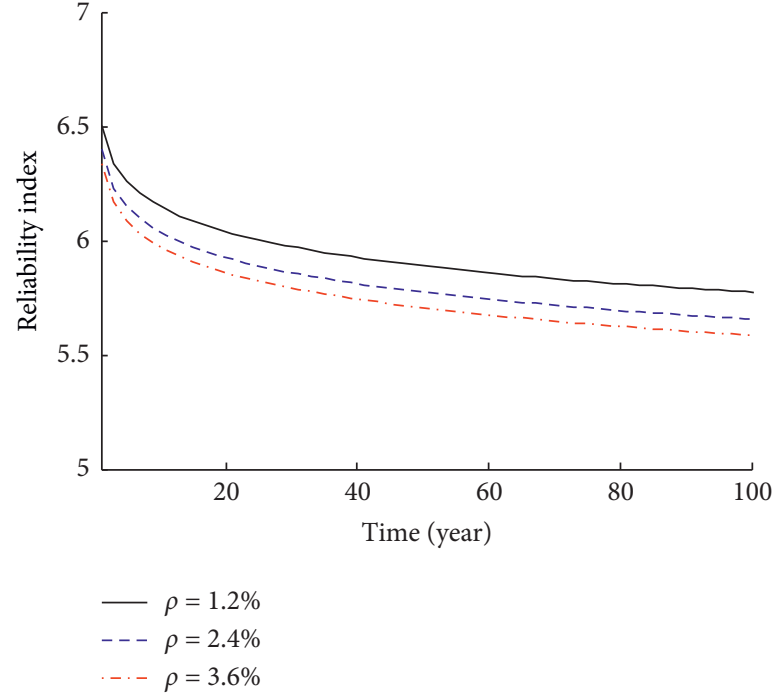

(b)

FIGURE 16: Reliability index of the continuous rigid-frame bridge based on the first-passage criterion of the girder deflection: (a) failure probability; (b) reliability index.

flow is essential for ensuring the bridge safety in service period.

\section{Conclusions}

This study developed the vehicle-bridge coupled vibration model to the dynamic reliability analysis of long-span bridges. A simplified analytical method was presented for evaluating probabilistic dynamic load effect induced by stochastic vehicle loads. The effectiveness of the proposed computational framework was demonstrated in the case study of a continuous rigid-frame bridge. Influence of the RRC, the bridge span length, and the traffic growth on the bridge deflection was investigated. The conclusions are summarised as follows:

(1) The mean value and the root mean square deflections induced by stochastic traffic loads are constants, which are uncorrelated with time. Therefore, the stochastic traffic-bridge coupled vibration is demonstrated as a stationary Gaussian random process, which can be treated as a long time history.

(2) The level-crossing is able to capture the probability characteristics of the dynamic traffic load effect and thus provides a connection between the dynamic effect and the probability model.

(3) The RRC will impact the probabilistic characteristics of traffic load effects. A poor RRC leads to larger number of level-crossings compared to a good RRC, and thus a poor RRC will amplify the maximum traffic load effect.

(4) The influence of the RRC on the dynamic effect is weakened with the increase of the bridge span length. This phenomenon can be explained by the theoretical basis that the bridge with a longer span length has a lower frequency, which will weaken the vehicle-bridge interaction.
(5) With consideration of the proportion of dense traffic flow as $1.2 \%, 2.4 \%$, and $3.6 \%$, the corresponding reliability indexes of the bridge in 100 years are 5.76, 5.62, and 5.60 , respectively. The proportion of dense vehicle flow has significant influence on the first-passage probability of the bridge deflection. Thus, the control of dense vehicle flow is essential for ensuring the bridge safety in service period.

Even though the proposed framework is verified for a rigidframe bridge, it can be applied for more types of bridges. However, more studies are necessary to improve the computational efficiency and accuracy. A more refined traffic-bridge interaction analysis approach instead of the simplified EDWL approach is critical to make the simulation more reasonable. In addition, the simulated traffic load effect needs to be compared with structural health monitoring data.

\section{Data Availability}

The original traffic monitoring data are available from the authors if necessary.

\section{Conflicts of Interest}

The authors declare that there are no conflicts of interest regarding the publication of this paper.

\section{Acknowledgments}

The authors would like to acknowledge the Management Department of the Nanxi Yangtze River Bridge duo for the help with the traffic data collection. This research was funded by the National Natural Science Foundation of China (Grant no. 51908068), the Open Fund of Engineering Research Center of Catastrophic Prophylaxis and Treatment of Road and Traffic Safety of Ministry of Education (Grant no. KFJ190403), 
Industry Key Laboratory of Traffic Infrastructure Security Risk Management in Changsha University of Science and Technology, (Grant no. 19KF03), Open Fund of Key Laboratory of Bridge Engineering Safety Control in Department of Education in Changsha University of Science and Technology (Grant no. 19KB02), National Science Foundation of Hunan Province (Grant nos. 2020JJ5140 and 2020JJ5589), and the Innovation Platform Open Fund Project of Hunan Education Department (19K002).

\section{References}

[1] A. S. Nowak, "Calibration of LRFD bridge code," Journal of Structural Engineering, vol. 121, no. 8, pp. 1245-1251, 1995.

[2] L. Deng, W. Yan, and L. Nie, "A simple corrosion fatigue design method for bridges considering the coupled corrosionoverloading effect," Engineering Structures, vol. 178, pp. 309-317, 2019.

[3] Y. Liu, X. Xiao, N. Lu, and Y. Deng, "Fatigue reliability assessment of orthotropic bridge decks under stochastic truck loading," Shock and Vibration, vol. 2016, Article ID 4712593, 10 pages, 2016.

[4] Y. Ma Yafei, Z. Guo, L. Wang Lei, and J. Zhang, "Probabilistic life prediction for reinforced concrete structures subjected to seasonal corrosion-fatigue damage," Journal of Structural Engineering, vol. 146, no. 7, 2020.

[5] Z. Guo, Y. Ma, L. Wang et al., "Crack propagation-based fatigue life prediction of corroded RC beams considering bond degradation," Journal of Bridge Engineering, vol. 25, no. $8,2020$.

[6] D. Skokandić, A. M. Ivanković, A. Žnidarič, and M. Srbic, "Modelling of traffic load effects in the assessment of existing road bridges," Građevinar, vol. 71, no. 12, pp. 1153-1165, 2019.

[7] X. Q. Zhu and S. S. Law, "Recent developments in inverse problems of vehicle-bridge interaction dynamics," Journal of Civil Structural Health Monitoring, vol. 6, no. 1, pp. 107-128, 2016.

[8] Y. Zhou and S. Chen, "Dynamic simulation of a long-span bridge-traffic system subjected to combined service and extreme loads," Journal of Structural Engineering, vol. 141, no. 9, pp. 1-18, 2015.

[9] S. R. Chen and J. Wu, "Dynamic performance simulation of long-span bridge under combined loads of stochastic traffic and wind," Journal of Bridge Engineering, vol. 15, no. 3, pp. 219-230, 2009.

[10] N. Lu, M. Noori, Y. Liu et al., "Lifetime deflections of longspan bridges under dynamic and growing traffic load," Journal of Bridge Engineering, vol. 22, no. 11, 2017.

[11] N. Lu, M. Noori, and Y. Liu, "First-passage probability of the deflection of a cable-stayed bridge under long-term sitespecific traffic loading," Advances in Mechanical Engineering, vol. 9, no. 1, pp. 1-10, 2017.

[12] E. J. Obrien, D. Cantero, B. Enright, and A. González, "Characteristic dynamic increment for extreme traffic loading events on short and medium span highway bridges," Engineering Structures, vol. 32, no. 12, pp. 3827-3835, 2010.

[13] C. Jiang, C. Wu, C. S. Cai, and W. Xiong, "Fatigue analysis of stay cables on the long-span bridges under combined action of traffic and wind," Engineering Structures, vol. 207, Article ID 110212, 2020.

[14] S. Li, S. Zhu, Y.-L. Xu, Z.-W. Chen, and H. Li, "Long-term condition assessment of suspenders under traffic loads based on structural monitoring system: application to the Tsing ma bridge,"
Structural Control and Health Monitoring, vol. 19, no. 1, pp. 82-101, 2012.

[15] C. C. Caprani, "Lifetime highway bridge traffic load effect from a combination of traffic states allowing for dynamic amplification," Journal of Bridge Engineering, vol. 18, no. 9, pp. 901-909, 2013.

[16] L. Shen, Y. Han, C. S. Cai et al., "Exceedance probability assessment of pedestrian wind environment based on multiscale coupling numerical simulation," Journal of Aerospace Engineering, vol. 33, no. 4, 2020.

[17] P. D. Spanos and I. A. Kougioumtzoglou, "Galerkin scheme based determination of first-passage probability of nonlinear system response," Structure and Infrastructure Engineering, vol. 10, no. 10, pp. 1285-1294, 2014.

[18] F. Sloothaak, V. Wachtel, and B. Zwart, "First-passage time asymptotics over moving boundaries for random walk bridges," Journal of Applied Probability, vol. 55, no. 2, pp. 627-651, 2018.

[19] A. Fenerci and O. Øiseth, "Strong wind characteristics and dynamic response of a long-span suspension bridge during a storm," Journal of Wind Engineering and Industrial Aerodynamics, vol. 172, pp. 116-138, 2018.

[20] D. Y. Zhu, Y. H. Zhang, D. Kennedy, and F. W. Williams, "Stochastic vibration of the vehicle-bridge system subject to non-uniform ground motions," Vehicle System Dynamics, vol. 52, no. 3, pp. 410-428, 2014.

[21] X. Yin, Y. Liu, L. Deng et al., "Dynamic behavior of damaged bridge with multi-cracks under moving vehicular loads," International Journal of Structural Stability and Dynamics, vol. 17, no. 2, 2017.

[22] S. R. Chen and C. S. Cai, "Equivalent wheel load approach for slender cable-stayed bridge fatigue assessment under traffic and wind: feasibility study," Journal of Bridge Engineering, vol. 12, no. 6, pp. 755-764, 2007.

[23] J. Wu and S. R. Chen, "Probabilistic dynamic behavior of a long-span bridge under extreme events," Engineering Structures, vol. 33, no. 5, pp. 1657-1665, 2011.

[24] N. Lu, Y. Ma, and Y. Liu, "Evaluating probabilistic traffic load effects on large bridges using long-term traffic monitoring data," Sensors, vol. 19, no. 22, 2019.

[25] S. O. Rice, "Mathematical analysis of random noise," Bell System Technical Journal, vol. 24, no. 1, pp. 46-156, 1945.

[26] L. Deng, W. Yan, and S. Li, "Computer modeling and weight limit analysis for bridge structure fatigue using OpenSEES," Journal of Bridge Engineering, vol. 24, no. 8, 2019.

[27] W. He, T. Ling, E. J. O’Brien, and L. Deng, "Virtual axle method for bridge weigh-in-motion systems requiring no axle detector," Journal of Bridge Engineering, vol. 24, no. 9, 2019.

[28] M. OBrien, A. Khan, D. McCrum et al., "Using statistical analysis of an acceleration-based bridge weigh-in-motion system for damage detection," Applied Sciences, vol. 10, no. 2, 2020.

[29] N. Lu, Y. Liu, and Y. Deng, "Fatigue reliability evaluation of orthotropic steel bridge decks based on site-specific weigh-in-motion measurements," International Journal of Steel Structures, vol. 19, no. 1, pp. 181-192, 2019.

[30] N. Lu, Probability model of dynamic responses and reliability assessment for stiffening girders of suspension bridges under random traffic flow, Ph.D. thesis, Changsha University of Science and Technology, Changsha, China, 2014.

[31] X. Yin, Y. Liu, G. Song et al., "Suppression of bridge vibration induced by moving vehicles using pounding tuned mass dampers," Journal of Bridge Engineering, vol. 23, no. 7, pp. 1-14, 2018. 